\title{
Elaboração de hidroxiapatita sinterizada a alta temperatura para aplicações odontológicas
}

\author{
Elaboration of high temperature sintered \\ hydroxyapatite for odontological applications
}

Enori Gemelli ${ }^{1}$, Claudinei Joaquim Franco ${ }^{1}$, Nelson Heriberto Almeida Camargo ${ }^{1}$

\footnotetext{
${ }^{1}$ Universidade do Estado de Santa Catarina, Centro de Ciências Tecnológicas, Departamento de Engenharia Mecânica, Campus Universitário, Bairro Zona Industrial Norte, cep: 89219-710, Joinville, SC, Brasil. e-mail: enori.gemelli@udesc.br, claudineijf@gmail.com,camargo@udesc.br
}

\section{RESUMO}

A hidroxiapatita estequiométrica é um material bioreabsorvível e tem sido utilizada para reparação óssea e jateamento de implantes de titânio. Contudo, a hidroxiapatita estequiométrica não é estável acima de $1130{ }^{\circ} \mathrm{C}$ a $1200{ }^{\circ} \mathrm{C}$ limitando a temperatura de tratamento térmico realizado no biomaterial para aumentar a resistência mecânica dos aglomerados obtidos do processo de síntese a temperatura ambiente. Sendo assim, o objetivo deste trabalho foi a elaboração de fosfato de cálcio com razão molar $\mathrm{Ca} / \mathrm{P}$ de 1,7 . Com esta razão molar $\mathrm{Ca} / \mathrm{P}$ é possível a formação de hidroxiapatita estável até aproximadamente $1360{ }^{\circ} \mathrm{C}$, de acordo com o diagrama de equilíbrio $\mathrm{CaO}-\mathrm{P}_{2} \mathrm{O}_{5}$. $\mathrm{O}$ fosfato de cálcio foi elaborado pelo método de síntese via úmida utilizando carbonato de cálcio e ácido fosfórico como matérias-primas. O material obtido da síntese é composto por partículas aglomeradas com tamanho entre $20 \mathrm{~nm}$ e $70 \mathrm{~nm}$, sendo que o tamanho dos aglomerados varia de alguns $\mu \mathrm{m}$ até aproximadamente $200 \mu \mathrm{m}$. Os resultados da análise térmica e da difração de raios-X mostraram que a hidroxiapatita é estável entre $750{ }^{\circ} \mathrm{C}$ e $1350{ }^{\circ} \mathrm{C}$. O tratamento térmico realizado a $1300{ }^{\circ} \mathrm{C}$ confirmou que não há transformação da hidroxiapatita em fosfato tricálcico acima de $1130{ }^{\circ} \mathrm{C}$ a $1200{ }^{\circ} \mathrm{C}$ como acontece com a hidroxiapatita estequiométrica. No tratamento térmico realizado a $1300{ }^{\circ} \mathrm{C}$ durante 1 hora obteve-se hidroxiapatita com $67 \%$ de porosidade enquanto que no tratamento de 4 horas, a mesma temperatura, a porosidade foi de $17 \%$. A hidroxiapatita com alta porosidade tem aplicação na reparação óssea enquanto que a hidroxiapatita mais compacta pode ser utilizada no jateamento de implantes de titânio. Estas aplicações são discutidas no trabalho.

Palavras-chave: fosfato de cálcio, hidroxiapatita, reparação óssea, jateamento de implantes de titânio.

\section{ABSTRACT}

Stoichiometric hydroxyapatite is a bioreabsorbable material and has been used for bone repair and shot blasting of titanium implants. However, the stoichiometric hydroxyapatite is not stable above $1130{ }^{\circ} \mathrm{C}$ to $1200{ }^{\circ} \mathrm{C}$, limiting the heat treatment performed on the biomaterial to increase the mechanical strength of the granules obtained from the synthesis process at room temperature. Therefore, the aim of this work was the elaboration of calcium phosphate with $\mathrm{Ca} / \mathrm{P}$ molar ratio of 1.7 . With this $\mathrm{Ca} / \mathrm{P}$ molar ratio, the formation of stable hydroxyapatite is possible up to approximately $1360{ }^{\circ} \mathrm{C}$, according to the $\mathrm{CaO}-\mathrm{P}_{2} \mathrm{O}_{5}$ equilibrium diagram. Calcium phosphate was prepared by the wet method of synthesis using calcium carbonate and phosphoric acid as raw materials. The material obtained from the synthesis consists of agglomerated particles with a size between $20 \mathrm{~nm}$ and $70 \mathrm{~nm}$, while the size of the agglomerates varied from a few microns to approximately $200 \mu \mathrm{m}$. The results of the thermal analysis and X-ray diffraction showed that the hydroxyapatite is stable between $750{ }^{\circ} \mathrm{C}$ and $1350{ }^{\circ} \mathrm{C}$. The heat treatment performed at $1300{ }^{\circ} \mathrm{C}$ confirmed that there is no transformation of hydroxyapatite into tricalcium phosphate above $1130{ }^{\circ} \mathrm{C}$ to $1200{ }^{\circ} \mathrm{C}$ as it happens for stoichiometric hydroxyapatite. In the heat treatment carried out at $1300{ }^{\circ} \mathrm{C}$ for 1 hour, hydroxyapatite was obtained with $67 \%$ of porosity whereas in the treatment of 4 hours at the same temperature the porosity was $17 \%$. Hydroxyapatite with high porosity has applications in bone repair whereas the more compact hydroxyapatite can be used in the blasting of titanium implants. These applications are discussed in the work. 
Keywords: calcium phosphate, hydroxyapatite, bone repair, blasting titanium implants.

\section{INTRODUÇÃO}

Implantes de titânio são amplamente utilizados em todo o mundo para reabilitar a perda dentária de pacientes. Contudo, em muitos casos, a perda óssea local não permite a colocação de implantes, necessitando de reparação óssea prévia. Além disso, perda óssea local também pode ser provocada por lesões ou processos inflamatórios de origem bacteriana. Embora a utilização de enxertos autógenos seja uma das práticas mais comuns para reparação óssea maxilar, a tendência futura é a utilização de biomateriais à base de fosfatos de cálcio sintéticos, pois os enxertos autógenos apresentam disponibilidade limitada e estão associados com dor e morbilidade local do paciente, podendo também resultar em infecção, perda de sensibilidade e hematoma. Enxertos alógenos e xenógenos também têm sido utilizados em odontologia, mas seus desempenhos biológicos são inferiores quando comparados com biomateriais sintéticos tais como hidroxiapatita (HA), fosfato tricálcico (TCP) ou bifásicos HA/TCP [1]. Além disso, a utilização de biomateriais de origem natural tem riscos de transmissão de doenças e de imunogenicidade [2, 3].

A hidroxiapatita sintética estequiométrica tem sido muito estudada para reparação de tecido ósseo por causa de sua similaridade química e estrutural com a parte mineral do osso. A razão molar $\mathrm{Ca} / \mathrm{P}$ da hidroxiapatita estequiométrica é 1,67 e ela é obtida por meio de tratamento térmico no pó de fosfato de cálcio elaborado pelos métodos de síntese realizados a temperatura ambiente. O pó de fosfato de cálcio obtido da síntese se transforma em hidroxiapatita acima de aproximadamente $750{ }^{\circ} \mathrm{C}$ e permanece estável até $1130{ }^{\circ} \mathrm{C}$ a $1200{ }^{\circ} \mathrm{C}$ [4, 5]. Normalmente é realizada uma calcinação a $900{ }^{\circ} \mathrm{C}$ por 2 horas para a obtenção de hidroxiapatita. O produto final de hidroxiapatita consiste de grânulos/aglomerados microporosos de diferentes tamanhos, os quais podem ser selecionados por peneiramento [6]. Contudo, os aglomerados de hidroxiapatita obtida nesta temperatura apresentam baixa resistência mecânica e podem ser facilmente esmagados durante o preenchimento do defeito ósseo. Assim, para minimizar esse adensamento é necessária uma sinterização parcial para aumentar a resistência mecânica dos grânulos ou aglomerados. Contudo, a hidroxiapatita estequiométrica não é termodinamicamente estável acima de $1130{ }^{\circ} \mathrm{C}$ a $1200{ }^{\circ} \mathrm{C}$ e se transforma em fosfato tricálcico [4, 5]. Sendo assim, o objetivo do estudo foi a elaboração de hidroxiapatita com razão molar $\mathrm{Ca} / \mathrm{P}$ de 1,7 . Com esta razão molar $\mathrm{Ca} / \mathrm{P}$ é possível a formação de hidroxiapatita estável até aproximadamente $1360{ }^{\circ} \mathrm{C}$, de acordo com o diagrama de equilíbrio $\mathrm{CaO}-\mathrm{P}_{2} \mathrm{O}_{5}$ [7].

$\mathrm{O}$ pó de fosfato de cálcio foi elaborado por síntese via úmida e sinterizado a $1300{ }^{\circ} \mathrm{C}$ por 1 hora e 4 horas. O tempo de sinterização foi escolhido para a obtenção de grânulos porosos e densos. Os porosos podem ser utilizados para enxerto ósseo enquanto que os densos podem ser utilizados para jateamento de implantes de titânio, pois em países desenvolvidos já existem empresas que fabricam implantes comerciais de titânio jateados com fosfato de cálcio [8].

O Brasil não produz implantes de titânio jateados com hidroxiapatita. As grandes vantagens do jateamento com hidroxiapatita sem a sua remoção são a eliminação do ataque ácido e a formação temporária de uma superfície bioativa. Se desejado, a HA pode ser removida em soluções ácidas ou básicas, mas bem menos concentradas do que aquelas utilizadas na remoção de alumina ou sílica tradicionalmente utilizadas no jateamento de implantes de titânio. Independentemente da remoção ou não, o jateamento com hidroxiapatita é um processo mais limpo do que o tradicional.

\section{ESTADO DA ARTE}

\subsection{Hidroxiapatita para reparação óssea}

Os fosfatos de cálcio microporosos são muito pesquisados e demonstram ser biomateriais potenciais em aplicações de reconstrução óssea maxilofacial, da estrutura dental e em aplicações ortopédicas. Isso está associado às propriedades biológicas que esses biomateriais oferecem [4-6, 9, 10]. Outro ponto diferencial desses biomateriais está relacionado à capacidade de solubilidade que eles apresentam quando aplicados em meio biológico. Eles permitem a liberação gradual de íons de cálcio e de fosfato e promovem a formação de um novo tecido ósseo $[9,10]$.

A resposta biológica da HA implantada em um defeito ósseo segue um mecanismo similar àquele da cura de uma fratura óssea: formação de hematoma, inflamação, adesão de células ósseas e formação de osso novo [11]. Durante a cura, a HA estimula o crescimento ósseo e proporciona estabilidade biológica dos tecidos reconstruídos por causa de suas propriedades biológicas, dentre as quais destacam-se: 
a) Biocompatibilidade. Tem sido bem documentado que a HA pode propiciar condições para crescimento de osso novo por meio do mecanismo de osteocondução sem causar qualquer toxicidade local ou sistêmica, inflamação ou resposta de corpo estranho $[11,12]$. Devido a sua excelente biocompatibilidade a neoformação óssea ocorre sem nenhuma reação adversa $[11,12]$.

b) Biodegradabilidade. A HA se dissolve em contato com os fluídos corpóreos por causa da atividade celular. Os osteoclastos secretam a enzima anidrase carbônica ou ácido lático diminuindo o pH local para 4 ou 5, e os osteoblastos, que estão diretamente envolvidos na formação óssea, aumentam o pH acima de 8,5 pela excreção de amônia [11, 13]. Além disso, no caso de partículas nanométricas, elas podem ser fagocitadas, e uma vez incorporadas no citoplasma, elas podem ser dissolvidas por ataque ácido e/ou por processo enzimático $[13,14]$.

c) Bioatividade. Quando implantada a HA reage com o meio fisiológico e cria ligações químicas entre o osso e o material implantado. A camada de apatita que se forma na interface biomaterial/tecido ósseo é a responsável pela ligação óssea [12].

A bioatividade de um biomaterial pode ser testada pela imersão do biomaterial em uma solução fisiológica sintética acelular $[15,16]$. Este tipo de teste foi normalizado pela ISO sob a designação ISO/FDIS 23317 com o objetivo de padronizar o ensaio e criar um método internacional para estudo comparativo.

d) Osteocondutividade. A osteocondutividade se refere ao crescimento ósseo sobre a superfície e dentro da porosidade do biomaterial. Este fenômeno é observado após a implantação de biomateriais de fosfato de cálcio como hidroxiapatita, fosfato tricálcico ou bifásicos de fosfatos de cálcio $[12,17]$. Esta propriedade tem sido investigada por meio de estudos in vivo e colocaram em evidência a excelente osteocondutividade destes biomateriais de fosfato de cálcio [12, 13].

e) Osteoinductividade. Também é conhecido que os fosfatos de cálcio têm a capacidade de estimular a proliferação e diferenciação de células ósseas, induzindo a formação de osso novo [11, 12]. Contudo, o mecanismo de osteoindução ainda não é conhecido. A dificuldade de estudo está no fato de que a osteoindução depende de um grande número de variáveis, as quais variam de um biomaterial a outro por causa das diferenças de composição, método e parâmetros de processamento dos biomateriais estudados.

Todos os fosfatos de cálcio microporosos tradicionalmente fabricados e estudados tais como a hidroxiapatita (HA), fosfato tricálcico (TCP) e bifásicos HA/TCP apresentam propriedades biológicas que são de grande interesse em medicina e odontologia para a reparação óssea. Estudos in vivo realizados em coelhos com HA, TCP e o bifásico $60 \%$ HA/40 \% TCP (\% em volume) revelaram que todos os biomateriais apresentaram um desempenho biológico superior quando comparados com os controles: Coágulo sanguíneo e um biomaterial comercial (BioOss) da empresa suíça Geistlich Biomaterials [1]. Outra constatação foi que a HA apresentou a melhor resposta óssea in vivo do que o bifásico e o TCP [1]. As análises histomorfométricas mostraram que a porcentagem de osso mineralizado após 45 dias foi de 36,9 \% para a HA, 31,2 \% para o bifásico, 31,3\% para o TCP, 26,4 \% para o BioOss e 3,6 \% para o coágulo. Após 90 dias foi de 49,5\% para a HA, $41,5 \%$ para o bifásico, $35,2 \%$ para o TCP e 6,3\% para o coágulo [1].

\subsection{Hidroxiapatita para jateamento de implantes de titânio}

Embora os fosfatos de cálcio tenham dureza menor do que os particulados comumente utilizados no jateamento de implantes dentários como é o caso da alumina ou da sílica, os trabalhos publicados mostram que o jateamento com particulados de fosfatos de cálcio também é tecnicamente possível, pois a microrrugosidade desejada para implantes dentários de titânio é pequena [18-20]. A dureza dos particulados é a principal propriedade para jateamento de implantes de titânio. No caso dos fosfatos de cálcio elaborados por meio de síntese a temperatura ambiente, os aglomerados formados são microporosos e apresentam baixa resistência mecânica. Por meio de tratamento térmico ocorre a sinterização e a densificação dos aglomerados. Quanto maior a temperatura e o tempo de tratamento térmico maior é o adensamento.

Um dos primeiros trabalhos sobre jateamento com fosfato de cálcio foi publicado por Citeao et al. [19]. Eles usaram um fosfato de cálcio bifásico composto de $75 \%$ de HA e $25 \%$ de $\beta$-TCP (\% em massa), com faixa granulométrica de $40 \mu \mathrm{m}$ a $80 \mu \mathrm{m}$, sendo que o jateamento foi realizado com pressão de ar de 8 bar sobre discos da liga de titânio Ti6Al4V usinados. Após o jateamento as amostras foram imersas em solução de $26 \%$ de ácido nítrico durante 1 hora a temperatura ambiente e em seguida enxaguadas com água deionizada. Para avaliar a rugosidade produzida pelo jateamento com fosfato de cálcio, amostras usinadas da liga também foram tratadas em solução de $26 \%$ de ácido nítrico durante 1 hora a temperatura ambiente. As medidas de rugosidade de superfície mostraram que a rugosidade média Ra da liga jateada e tratada em ácido nítrico foi de $1,57 \mu \mathrm{m} \pm 0,07 \mu \mathrm{m}$ enquanto que a rugosidade média Ra da liga somente tratada em ácido nítrico foi de $0,58 \mu \mathrm{m} \pm 0,05 \mu \mathrm{m}$, basicamente a mesma rugosidade do material usinado. $\mathrm{O}$ tratamento ácido 
dissolveu os particulados de fosfato de cálcio impregnados e praticamente não alterou a rugosidade das amostras $[19,20]$.

Em um trabalho mais recente Lukaszewska-Kuska et al. [18] realizaram ensaios in vitro em amostras de titânio jateadas com alumina ou com fosfato de cálcio para estudar a influência dos tratamentos de superfície na viabilidade e diferenciação de osteoblastos humanos. Foram avaliados 5 tipos de modificações da superfície do titânio: Usinado (grupo 1), jateado com alumina (grupo 2), jateado com alumina e ataque ácido (grupo 3), jateado com fosfato de cálcio (grupo 4) e jateado com fosfato de cálcio e ataque ácido (grupo 5). $\mathrm{O}$ fosfato de cálcio utilizado foi um bifásico composto de $70 \% \mathrm{HA} / 30 \% \mathrm{TCP}$ com tamanho de grão inferior a $300 \mu \mathrm{m}$. Os particulados de alumina tinham tamanho de grão entre $53 \mu \mathrm{m}$ a $75 \mu \mathrm{m}$. Após os tratamentos de superfície, todas as amostras foram lavadas ultrasonicamente com um surfactante por 15 min a $55{ }^{\circ} \mathrm{C}$, seguidas por 15 min a $22{ }^{\circ} \mathrm{C}$ em 2-propanol, desinfetadas por 15 min a $22{ }^{\circ} \mathrm{C}$ e lavadas duas vezes em água destilada por $15 \mathrm{~min}$ a $55{ }^{\circ} \mathrm{C}$. Para os ensaios in vitro as amostras foram embaladas e esterilizadas por radiação.

As análises de superfície mostraram que uma quantidade significativa de particulados de fosfato de cálcio permaneceu impregnada na superfície do titânio jateado com o bifásico de fosfato de cálcio após a lavagem. A rugosidade de superfície em termos de Sa foi de $0,182 \mu \mathrm{m} \pm 0,056 \mu \mathrm{m}, 0,713 \mu \mathrm{m} \pm 0,036 \mu \mathrm{m}$, $0,748 \mu \mathrm{m} \pm 0,128 \mu \mathrm{m}, 0,664 \mu \mathrm{m} \pm 0,077 \mu \mathrm{m}$ e $0,507 \mu \mathrm{m} \pm 0,065 \mu \mathrm{m}$ para os grupos $1,2,3,4$ e 5 , respectivamente [18].

Os ensaios in vitro mostraram que as superfícies tratadas são atóxicas $[18,20]$ e que a viabilidade celular (ensaio MTT) das amostras jateadas com alumina (grupo 2) é maior do que aquelas jateadas com fosfato de cálcio (grupo 4). De acordo com os autores do trabalho esta pequena diferença pode estar relacionada com a diferença de rugosidade e de hidrofilidade de superfície das amostras [18]. Por outro lado, a diferenciação celular (atividade ALP) é maior nas amostras jateadas com fosfato de cálcio do que nas amostras jateadas com alumina. A atividade de fosfatase alcalina (atividade ALP) indica a diferenciação osteogênica, a formação e mineralização óssea [18].

Deve-se ressaltar também que em países desenvolvidos existem várias empresas que fabricam implantes de titânio com jateamento de fosfato de cálcio. A morfologia de superfície dos implantes de titânio jateados com fosfato de cálcio é similar àquela do titânio jateado com alumina [8, 18, 19].

\section{MATERIAIS E MÉTODOS}

O carbonato de cálcio $\left(\mathrm{CaCO}_{3}\right)$, da marca Vetec Química Fina e com pureza de 99,8\%, foi calcinado a 900 ${ }^{\circ} \mathrm{C}$ por 2 horas para obtenção do óxido de cálcio. O óxido de cálcio e o ácido fosfórico (com $85 \%$ de pureza) foram os precursores utilizados para síntese da hidroxiapatita.

O processo de fabricação do pó de hidroxiapatita consistiu na dissolução do óxido de cálcio em água destilada por agitação mecânica durante 2 horas. A solução coloidal foi mantida em suspensão por agitação durante a adição controlada de ácido fosfórico até a razão molar $\mathrm{Ca} / \mathrm{P}$ de 1,7. A solução coloidal permaneceu por agitação mecânica durante 5 horas seguida de secagem em evaporador rotativo a $70{ }^{\circ} \mathrm{C}$ e $540 \mathrm{rpm}$. O pó seco obtido foi caracterizado por análise granulométrica, análise térmica, difração de raios-X e microscopia eletrônica de varredura.

Por último, o pó seco obtido foi sinterizado a $1300{ }^{\circ} \mathrm{C}$ por 1 hora e 4 horas e em seguida caracterizado por difração de raios-X e microscopia eletrônica de varredura.

A distribuição do tamanho das partículas (DTP) do pó obtido da síntese foi medida por meio de um analisador de partículas por difração LASER da marca Shimadzu, modelo SALD-7001 (Japão). O comprimento de onda do leitor LASER é de $405 \mathrm{~nm}$, permitindo a medição de tamanhos de partículas entre $10 \mathrm{~nm}$ e $500 \mathrm{~nm}$. Para as medidas experimentais as partículas foram dispersadas em água destilada com descarga ultrasônica durante 2 min.

Os ensaios de análise térmica diferencial (ATD) foram realizados em um equipamento da marca Netzsch, modelo Jupiter STA 449C (Alemanha). Os ensaios foram feitos em atmosfera de ar sintético entre a temperatura ambiente até $1400{ }^{\circ} \mathrm{C}$ com taxa de aquecimento de $5{ }^{\circ} \mathrm{C} / \mathrm{min}$. Um difractômetro da marca Shimadzu, modelo XRD 6000 (Japão), com fonte de radiação $\mathrm{CuK}_{\alpha}$ foi usado par identificar as fases dos materiais. Foi utilizada uma tensão de $40 \mathrm{kV}$ e intensidade de corrente de $30 \mathrm{~mA}$, intervalo angular $(\theta)$ de varredura de $20^{\circ}$ a $55^{\circ}$ e velocidade do goniômetro de $2^{\circ} / \mathrm{min}$ em função de $2 \theta$. As análises de microscopia eletrônica de varredura (MEV) foram realizadas em um microscópio da marca Zeiss, modelo DSM 940A (Alemanha). 
A porosidade aberta foi medida pelo método de Arthur [21] nos materiais sinterizados. O procedimento consistiu em pesar a amostra seca ao ar em $\mathrm{g}\left(\mathrm{M}_{\mathrm{I}}\right)$. Posteriormente a amostra foi embebida em xileno, removida do meio líquido e pesada ao ar (em g) após retirar o excesso de xileno da superfície $\left(\mathrm{M}_{\mathrm{e}}\right)$. Em seguida, a amostra foi pesada novamente $(\mathrm{em} \mathrm{g})$, mas submersa em água destilada $\left(\mathrm{M}_{\mathrm{a}}\right)$. A porosidade aberta (PA) foi calculada por meio da equação (1):

$$
P A=\frac{\left(M_{e}-M_{I}\right) d_{e}}{\left(M_{e}-M_{a}\right) d_{x}} 100
$$

Onde $\mathrm{d}_{\mathrm{x}}$ é a densidade do xileno $\left(0,8802 \mathrm{~g} / \mathrm{cm}^{3}\right)$ e $\mathrm{d}_{\mathrm{e}}$ é a densidade da água $\left(1 \mathrm{~g} / \mathrm{cm}^{3}\right)$.

\section{RESULTADOS E DISCUSSÕES}

\subsection{Análise granulométrica do pó}

Após a secagem em evaporador rotativo foi coletada uma amostra de pó do fosfato de cálcio para análise granulométrica. A análise revelou que o biomaterial tinha uma dispersão de tamanho de partículas entre 20 $\mathrm{nm}$ e $70 \mathrm{~nm}$, apresentando um tamanho médio de aproximadamente $45 \mathrm{~nm}$. O pó seco se encontrava na forma de aglomerados de partículas que foram previamente dispersados por ultrassom antes da análise por difração LASER.

A Figura 1a mostra parte dos aglomerados de partículas que se formaram durante a secagem da suspensão coloidal. Para o preenchimento de defeitos ósseos esses aglomerados podem ser selecionados por peneiramento. A imagem ampliada de um desses aglomerados (Figura 1b) mostra que eles são constituídos por particulados nanométricos arredondados aglutinados na forma de uma estrutura porosa, características que favorecem os processos de osteoindução e osteocondução. As análises realizadas no MEV mostraram que o tamanho dos aglomerados varia de alguns micrometros até aproximadamente $200 \mu \mathrm{m}$.
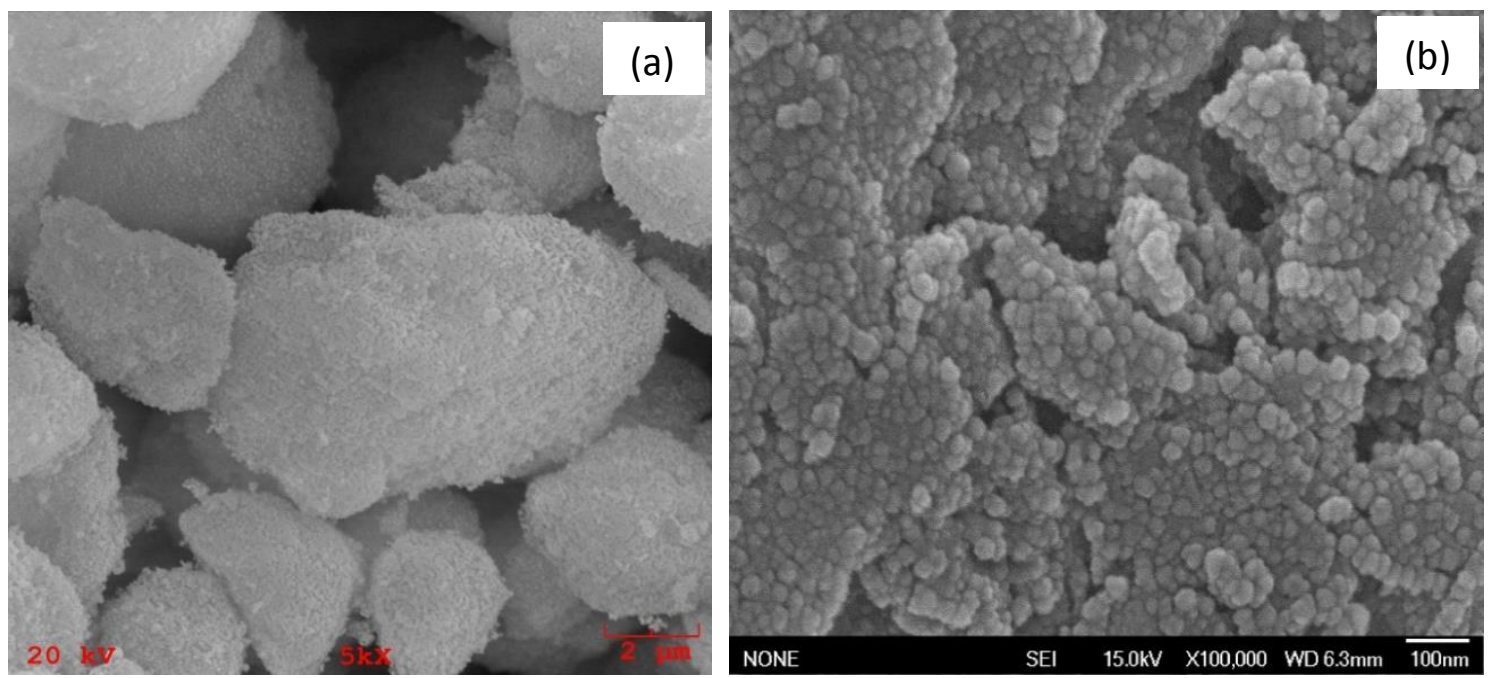

Figura 1: Aglomerados formados após a secagem da solução coloidal (a) e morfologia da superfície de um aglomerado do fosfato de cálcio (b).

\subsection{Análise térmica}

A Figura 2 mostra a curva representativa da análise térmica diferencial da amostra do pó de fosfato de cálcio recuperado do evaporador rotativo. O pico endotérmico a aproximadamente $65{ }^{\circ} \mathrm{C}$ que aparece na curva do fosfato de cálcio está relacionado com a evaporação da água adsorvida na superfície do biomaterial. O pico exotérmico a $345,3{ }^{\circ} \mathrm{C}$ está associado com a perda de água (desidroxilação) do fosfato de cálcio hidratado [4, 5]. O pico a aproximadamente $736,5^{\circ} \mathrm{C}$ é devido à cristalização completa do fosfato de cálcio semi-cristalino em hidroxiapatita (HA) $[4,5]$. O pico a aproximadamente $1351,7{ }^{\circ} \mathrm{C}$ está relacionado com a transformação da hidroxiapatita em fosfato tetracálcico $\left(\mathrm{Ca}_{4} \mathrm{O}\left(\mathrm{PO}_{4}\right)_{2}\right)$ [22]

Os resultados mostram que a razão molar $\mathrm{Ca} / \mathrm{P}$ de 1,7 não afeta a temperatura de formação da hidroxiapatita. As análises térmicas realizadas em pós de fosfatos de cálcio sintetizados com razão molar 
$\mathrm{Ca} / \mathrm{P}$ de 1,67 mostraram que a cristalização do fosfato de cálcio em hidroxiapatita ocorre entre $730{ }^{\circ} \mathrm{C}$ a 750 ${ }^{\circ} \mathrm{C}[4,5]$.

Outra constatação importante na curva da análise térmica foi a ausência do pico exotérmico referente a transformação de fase da hidroxiapatita em fosfato tricálcico alfa $(\alpha-\mathrm{TCP})$. Esta transformação ocorre a aproximadamente $1130{ }^{\circ} \mathrm{C}$ a $1200{ }^{\circ} \mathrm{C}$ em pós de fosfato de cálcio com razão molar $\mathrm{Ca} / \mathrm{P}$ de 1,67 [4, 5]. Portanto, os resultados mostram que para a obtenção de hidroxiapatita estável até aproximadamente $1350{ }^{\circ} \mathrm{C}$ é preciso elaborar fosfato de cálcio com razão molar $\mathrm{Ca} / \mathrm{P}$ de 1,7 .

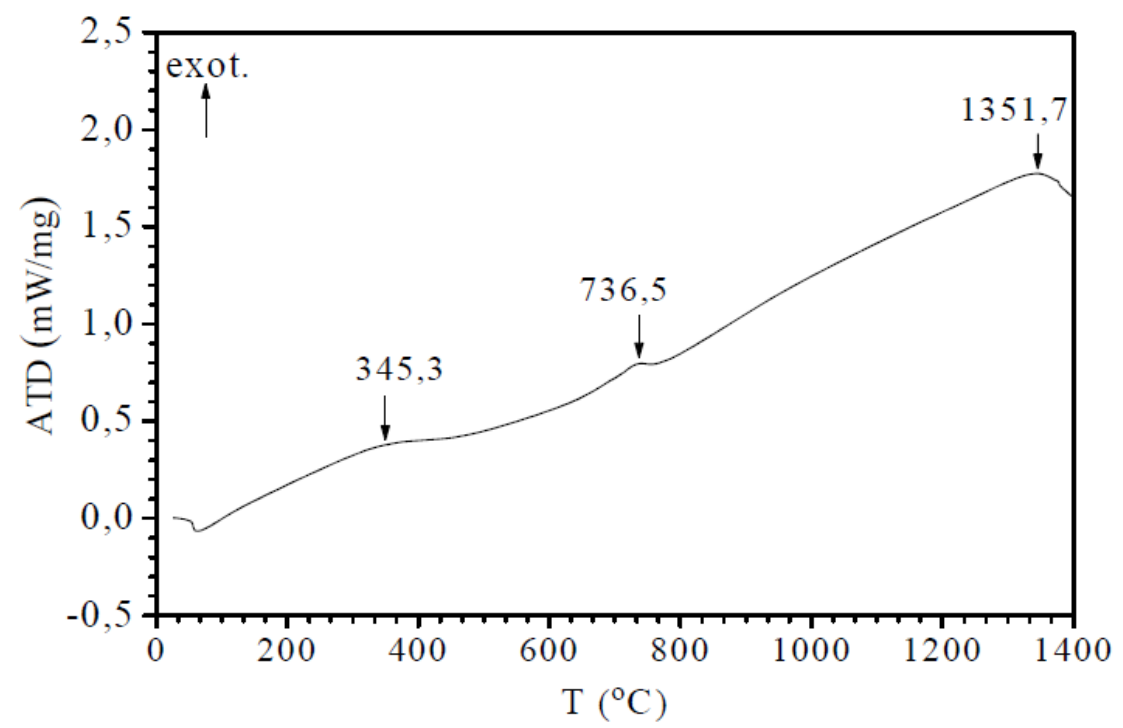

Figura 2: Análise térmica diferencial (ATD) realizada no pó de fosfato de cálcio com razão molar $\mathrm{Ca} / \mathrm{P}$ de 1,7 .

\subsection{Difração de raios- $X$}

De acordo com a análise térmica da Figura 2 é necessário realizar um tratamento térmico acima de $736,5{ }^{\circ} \mathrm{C}$ para identificar as fases cristalinas da hidroxiapatita por difração de raios-X (DRX). A calcinação a $900{ }^{\circ} \mathrm{C}$ é o tratamento térmico convencional realizado nos biomateriais à base de fosfato de cálcio para a formação das fases cristalinas $[4,6]$. Além da calcinação também é comum realizar um tratamento térmico para sinterização parcial dos biomateriais $[4,6]$.

De acordo com a Figura 2, o tratamento térmico pode ser realizado acima de $1200{ }^{\circ} \mathrm{C}$ até aproximadamente $1350{ }^{\circ} \mathrm{C}$ sem que haja risco de transformação da hidroxiapatita em fosfato tricálcico. Para verificar, o tratamento térmico foi realizado a $1300{ }^{\circ} \mathrm{C}$ durante 1 hora e 4 horas. As análises de difração de raios-X mostraram que os resultados são os mesmos independentemente do tempo de tratamento térmico. As Figuras 3 e 4 são difratogramas representativos de difração de raios- $X$ dos biomateriais tratados durante 1 hora e 4 horas a $1300{ }^{\circ} \mathrm{C}$, comprovando que a hidroxiapatita é estável nesta temperatura. A identificação dos picos foi realizada por meio da ficha JCPDS 74-0565, que corresponde à hidroxiapatita cristalina com estrutura hexagonal e plano principal de difração em (211). 


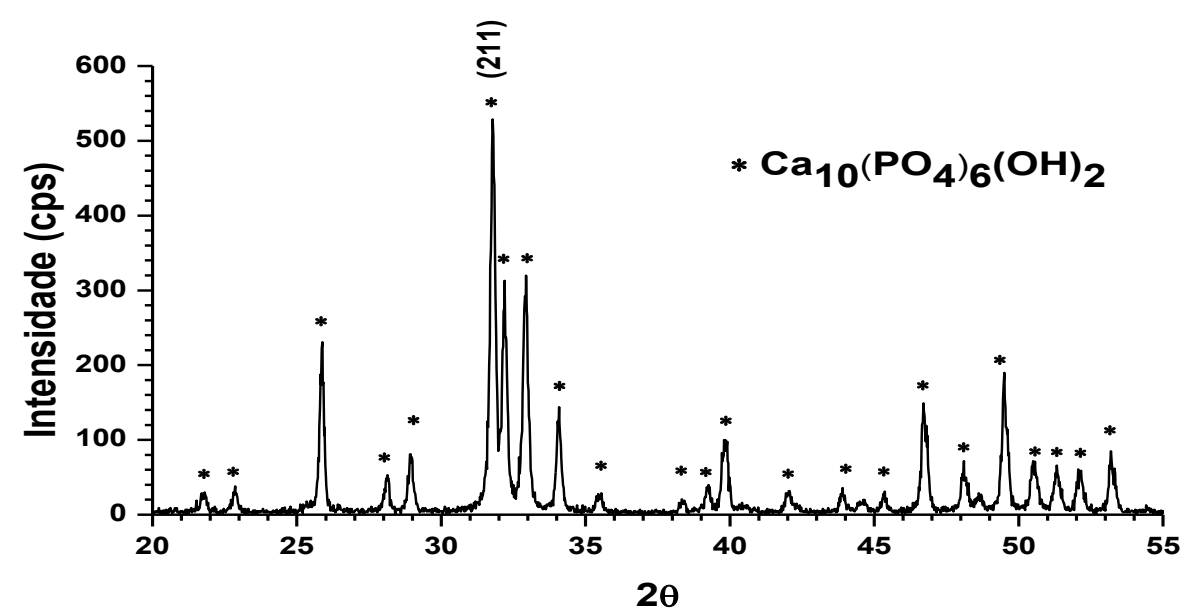

Figura 3: Difratograma de raios-X realizado no pó de fosfato de cálcio tratado a $1300{ }^{\circ} \mathrm{C}$ durante 1 hora.

\subsection{Porosidade aberta}

A porosidade é uma das principais características de um biomaterial para que ele possa promover a osteocondução de células ósseas. Porém, durante o preenchimento do defeito ósseo pode haver o esmagamento dos grânulos/aglomerados do biomaterial devido à manipulação, provocando um adensamento do enxerto. Assim, para minimizar esse adensamento normalmente é feita uma sinterização parcial para aumentar a resistência mecânica dos grânulos ou aglomerados formados durante a secagem da suspensão coloidal dos particulados obtidos pelo processo de síntese. Os pós fabricados também podem ser preparados na forma de grânulos por peneiramento [6]. Contudo, se por um lado a sinterização aumenta a resistência mecânica, por outro lado ela diminui a porosidade por causa da densificação do biomaterial. Assim, as condições de tratamento térmico devem ser investigadas de modo a resultar em uma maior resistência mecânica, mas sem comprometer demasiadamente a porosidade do biomaterial. Para biomateriais de HA com razão molar $\mathrm{Ca} / \mathrm{P}$ de 1,67 essa sinterização parcial normalmente é realizada a $1100{ }^{\circ} \mathrm{C}$ durante um período de 2 horas a 3 horas [4-6]. Tendo em vista que neste trabalho a temperatura de sinterização escolhida foi de $1300{ }^{\circ} \mathrm{C}$, o tempo de tratamento térmico foi reduzido para 1 hora para a elaboração do biomaterial para reparação óssea. Para a mesma temperatura de sinterização parte do pó de fosfato de cálcio foi tratado por 4 horas para a densificação dos aglomerados. Neste caso os particulados podem ser utilizados para o jateamento da superfície de implantes de titânio. Para este tipo de aplicação, a sinterização a temperaturas mais elevadas é necessária para diminuir o tempo de tratamento térmico.

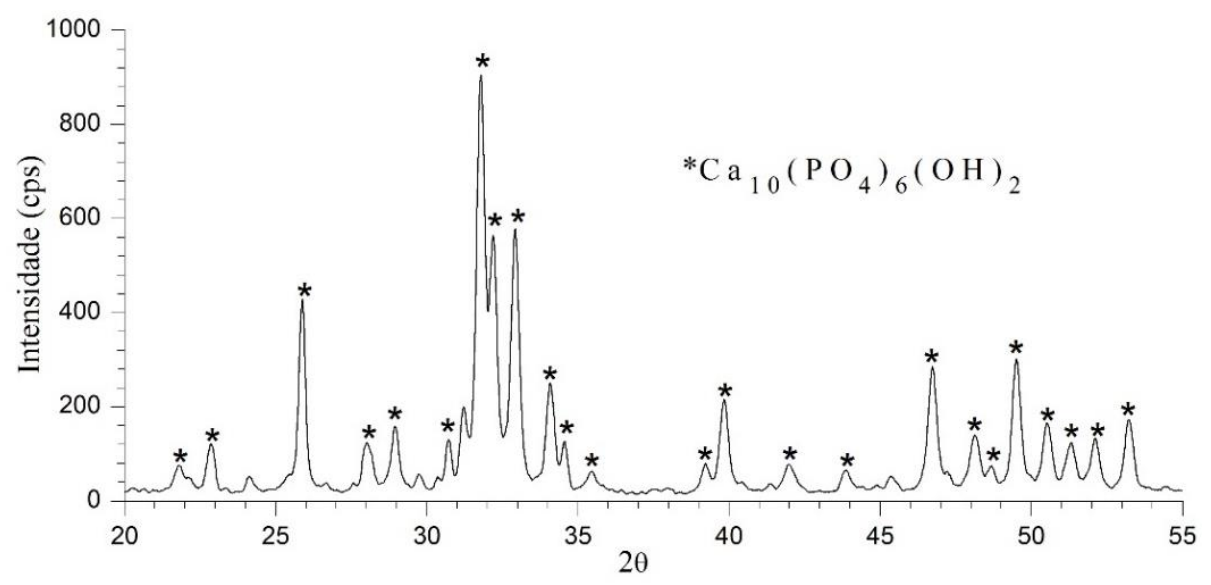

Figura 4: Difratograma de raios-X realizado no pó de fosfato de cálcio tratado a $1300{ }^{\circ} \mathrm{C}$ durante 4 horas.

Os resultados de porosidade aberta foram de 67,25\% $\%$ 2,87 \% para as amostras tratadas durante 1 hora e de $17,57 \% \pm 2,54 \%$ para as amostras tratadas durante 3 horas. Estes valores de porosidade aberta mostram que é possível controlar a porosidade por meio do tempo de tratamento térmico para uma determinada temperatura. Dependendo da finalidade, pode-se fabricar um biomaterial poroso para reparação óssea, ou particulados mais densos para jateamento de implantes de titânio. Materiais mais compactos para jateamento 
podem ser obtidos com maior tempo de tratamento ou aumentando a temperatura, mas até aproximadamente $1350{ }^{\circ} \mathrm{C}$, pois acima desta temperatura a hidroxiapatita não é mais estável.

A porosidade dos fosfatos de cálcio com razão molar Ca/P de 1,5 e 1,67, compactados a $30 \mathrm{MPa}$ e sinterizados entre $1100{ }^{\circ} \mathrm{C}$ e $1200{ }^{\circ} \mathrm{C}$ durante 2 horas fica entre $40 \%$ e $45 \%$ [4, 23]. Neste trabalho, o fosfato de cálcio tratado termicamente a $1300{ }^{\circ} \mathrm{C}$ durante 1 hora apresentou porosidade aberta bem maior porque o biomaterial não foi compactado. A compactação densifica o material por meio mecânico e aumenta a área de contato entre os particulados, favorecendo também a sinterização do biomaterial durante o tratamento térmico. A maior porosidade do biomaterial favorece a dissolução gradual da hidroxiapatita e, consequentemente, a formação de osso novo. A solubilidade ocorre pelo processo de dissociação iônica, com liberação de íons de cálcio e fosfato, e pelo surgimento de pontes de $\mathrm{OH}^{-}$na interface biomaterial meio biológico. Este mecanismo conduz à redução da superfície de grãos e ampliação da microporosidade, permitindo melhor oxigenação dentro da microporosidade do biomaterial decorrente da presença de pontes de $\mathrm{OH}^{-}$nas interfaces de grãos e de microporos. Este mecanismo de solubilização favorece a vascularização, a proliferação celular na superfície de grãos e de microporos, resultando na substituição do biomaterial por um novo tecido ósseo [24, 25]. Portanto, a porosidade do biomaterial é uma das principais características físicas para a reparação óssea.

A Figura 5 mostra imagens representativas da superfície de grânulos da hidroxiapatita sinterizada a $1300{ }^{\circ} \mathrm{C}$ durante 1 hora (Figura 5a) e 4 horas (Figura 5b). Pode-se observar que a amostra tratada durante 1 hora teve uma boa sinterização nos pontos de contato dos particulados, formando uma rede de porosidade interconectada com tamanhos submicrométricos, servindo de arcabouço para o desenvolvimento celular em meio fisiológico. Já na amostra tratada durante 3 horas houve coalescência de grãos e fechamento significativo da porosidade. Não é uma amostra que serve para reparação óssea por causa da baixa porosidade, mas serve como material para jateamento de implantes de titânio.
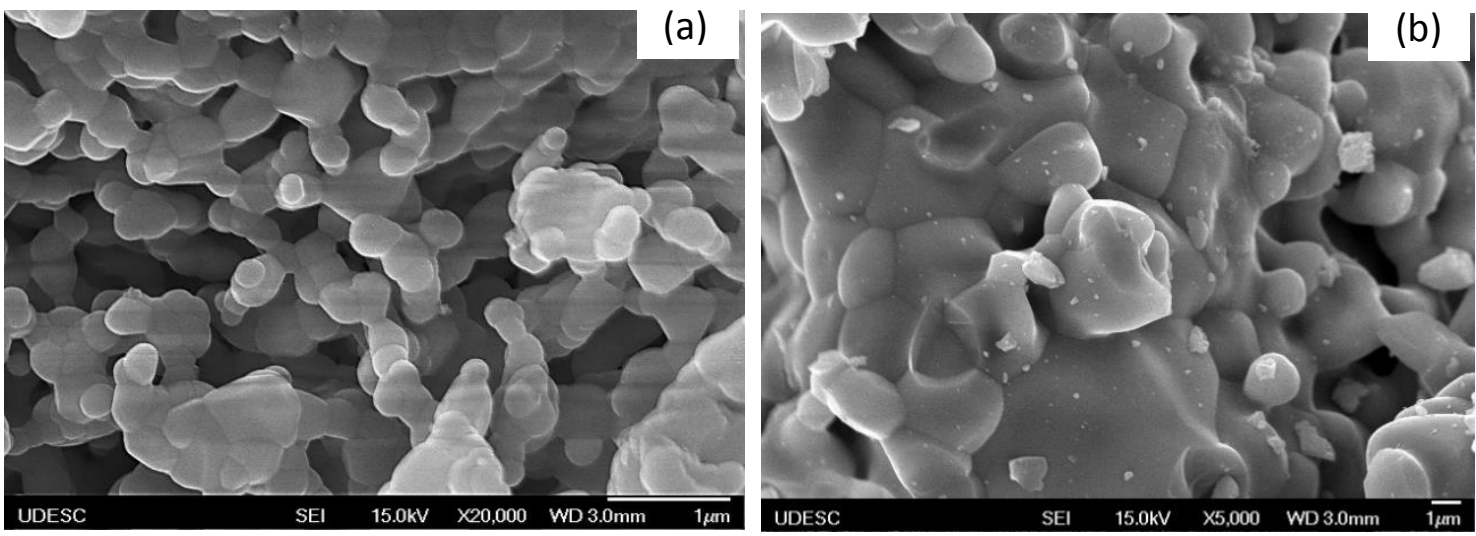

Figura 5: Morfologia da hidroxiapatita sinterizada a $1300{ }^{\circ} \mathrm{C}$ durante (a) 1 hora e (b) 4 horas.

\section{CONCLUSÕES}

Este trabalho mostrou que é possível elaborar hidroxiapatita com razão molar $\mathrm{Ca} / \mathrm{P}$ igual a 1,7 pelo método de síntese via úmida. O fosfato de cálcio obtido da síntese é formado por aglomerados microporosos com tamanhos que variam de alguns micrometros até aproximadamente $200 \mu \mathrm{m}$. Os aglomerados são formados por partículas nanométricas com tamanhos entre $20 \mathrm{~nm}$ e $70 \mathrm{~nm}$.

$\mathrm{O}$ fosfato de cálcio obtido da síntese se transforma completamente em hidroxiapatita cristalina a aproximadamente $750{ }^{\circ} \mathrm{C}$. A hidroxiapatita se mantém estável até aproximadamente $1350{ }^{\circ} \mathrm{C}$. Portanto, não há transformação da hidroxiapatita em fosfato tricálcico entre $1130{ }^{\circ} \mathrm{C}$ a $1200{ }^{\circ} \mathrm{C}$ como acontece com a hidroxiapatita elaborada com razão molar $\mathrm{Ca} / \mathrm{P}$ igual a 1,67.

Os aglomerados tratados a $1300{ }^{\circ} \mathrm{C}$ durante 1 hora apresentaram sinterização parcial aumentando a resistência mecânica dos grânulos. A porosidade aberta dos aglomerados foi de aproximadamente 67 \%. Já os aglomerados tratados na mesma temperatura durante 4 horas apresentaram uma sinterização bem maior com fechamento significativo da porosidade, resultando em uma porosidade aberta próxima a $17 \%$.

Com estes resultados fica evidente que a hidroxiapatita sinterizada durante 1 hora apresenta características apropriadas para reparação de defeitos ósseos, enquanto que a hidroxiapatita sinterizada durante 4 horas pode ser utilizada para jateamento de implantes de titânio. 


\section{BIBLIOGRAFIA}

[1] LEVANDOWSKI JUNIOR, N., "Análise comparativa de diferentes substitutos ósseos sintéticos microporosos em calvária de coelhos", Tese de doutorado em Ciência e Engenharia de Materiais, Universidade do Estado de Santa Catarina, Joinville, 2014.

[2] LEGEROS, R.Z., "Properties of osteoconductive biomaterials: calcium phosphates", Clinical Orthopaedics and Related Research, v. 395, pp. 81-98, 2002.

[3] KEITH-JR, J.D., PETRUNGARO, P., LEONETTI, J.A., "Clinical and histologic evaluation of a mineralized block allograft: results from the developmental period (2001-2004)", International Journal of Periodontics and Restorative Dentistry, v. 26, pp. 321-327, 2006.

[4] DALMÔNICO, G.M.L., "Síntese e caracterização de fosfato de cálcio e de hidroxiapatita: elaboração de composições bifásicas HA/TCP- $\beta$ para aplicações biomédicas", Dissertação de mestrado em Ciência e Engenharia de Materiais, Universidade do Estado de Santa Catarina, Joinville, 2011.

[5] de OLIVEIRA, D.M.P., "Síntese e caracterização de pós de fosfato tricálcico- $\beta$ e de hidroxiapatita: elaboração de bifásicos HA/TCP- $\beta$ para aplicações como substituto ósseo", Dissertação de mestrado em Ciência e Engenharia de Materiais, Universidade do Estado de Santa Catarina, Joinville, 2010.

[6] ALMEIDA CAMARGO, N.H., de LIMA, S.A., GEMELLI, E., "Synthesis and characterization of hydroxyapatite/ $\mathrm{TiO}_{2 \mathrm{n}}$ nanocomposites for bone tissue regeneration", American Journal of Biomedical Engineering, v. 2, pp. 41-47, 2012.

[7] BIGNON, A., "Optimisation de la structure poreuse d'implants en phosphate de calcium pour application de complement osseux et relargage in situ d'un principe actif", Tese de doutorado em Ciência e Engeharia de Materiais, Institut National des Sciences Appliquées de Lyon, Lyon (França), 2002.

[8] CHRCANOVIC, B.R., PEDROSA, A.R., MARTINS, M.D., "Chemical and topographic analysis of treated surfaces of five different commercial dental titanium implants", Materials Research, v. 15, pp. 372382, 2012.

[9] GHANAATI, S., BARBECK, M., ORTH, C., WILLERSHAUSEN, I., et al., "Influence of tricalcium phosphate granule size and morphology on tissue reaction in vivo", Acta Biomaterialia, v. 6, pp. 4476-4487, 2010.

[10] SROKA-BARTNICKA, A., BORBOWSKI, L., GINALSKA, G., et al., "Structural transformation of synthetic hydroxyapatite under simulated in vivo conditions studied with ATR-FTIR spectroscopic imaging", Spectrochimica Acta Part A: Molecular and Biomolecular Spectroscopy, v. 171, pP. 155-161, 2017.

[11] CANILLAS, M., PENA, P., de AZA , A.H., et al., "calcium phosphates for biomedical applications", Boletin de la Sociedad Española de Cerámica y vítreo, v. 56, pp. 91-112, 2017.

[12] BOULER, J.M., PILET, P., GAUTHIER, O., et al., "Biphasic calcium phosphate ceramics for bone reconstruction: A review of biological response", Acta Biomaterialia, v. 53, pp. 1-12, 2017.

[13] DOROZHKIN, S.V., "Self-setting calcium orthophosphate formulations", Journal of Functional Biomaterials, v. 4, pp. 2019-311, 2013.

[14] DOROZHKIN, S.V., "Calcium orthophosphate-based bioceramics", Materials, v. 6, pp. 3840-3942, 2013.

[15] SOBCZAK-KUPIEC, A., OLENDER, E., MALINE, D., et al., "Effect of calcination parameters on behavior of bone hydroxyapatite in artificial saliva and its biosafety", Materials Chemistry and Physics, v. 206, pp. 158-165, 2018.

[16] GALlO, M., TADIER, S., MEILlE, S., et al., "Resorption of calcium phosphate materials: Considerations on the in vitro evaluation", Journal of the European Ceramic Society, v. 38, pp. 899-914, 2018.

[17] KUBASIEWICZ-ROSS, P., HADZIK, J., SEELIGER, J., et al., "New nano-hydroxyapatite in bone defect regeneration: A histological study in rats", Annals of Anatomy, v. 213, pp. 83-90, 2017.

[18] LUKASZEWSKA-KUSKA, M.; WIRSTLEIN, P.; MAJCHROWSKI, R.; DOROCKA-BOBKOWSKA, B., "Osteoblastic cell behavior on modified titanium surfaces", Micron, v. 105, pp. 55-63, 2018.

[19] CITEAO, A., GUICHEUX, J., VINATIER, C., et al., "In vitro biological effects of titanium rough surface obtained by calcium phosphate grit blasting", Biomaterials, v. 26, pp. 157-165, 2005.

[20] GOYENVAlle, E., AGUADO, E., COGNET, R., et al., "Calcium phosphate ceramic blasting on titanium surface improve bone ingrowth", Key Engineering Materials, v. 361-363, pp. 1351-1354, 2007. 
[21] PENNINGS, E.C.M., GRELINER, W., "Precise non destrutive determination of the density of ceramic", Journal of American Ceramic Society, v. 72, pp. 1268-1270, 1989.

[22] DOROZHKIN, S. V., "Multiphasic calcium orthophosphate $\left(\mathrm{CaPO}_{4}\right)$ bioceramics and their biomedical applications", Ceramic International, v. 42, pp. 6529-6554, 2016.

[23] MIZUBUTI,Y.E., "Síntese e caracterização de fosfatos de cálcio: Elaboração de biomateriais nanocompósitos $\mathrm{HA} / \mathrm{TiO}_{2}$ para uso como substituto ósseo", Dissertação de mestrado em Ciência e Engenharia de Materiais, Universidade do Estado de Santa Catarina, Joinville, 2018.

[24] KIM, S.; LEE, Y.-K., "Effects of biphasic calcium phosphate bone substitute on circumferential bone defects around dental implants in dogs", The International Journal of Oral \& Maxillofacial Implants, v. 26, pp. 265-273, 2011.

[25] GARRIDO, C.A., LOBO, S.E., TURBIO, F.M., et al., "Biphasic calcium phosphate bioceramics for orthopaedic reconstructions: Clinical outcomes”, International Journal of Biomaterials, v. 2011, pp. 1-9, 2011.

ORCID

Enori Gemelli

Claudinei Joaquim Franco

https://orcid.org/0000-0003-0881-4562

Nelson H A Camargo

https://orcid.org/0000-0002-6367-4120

https://orcid.org/0000-0002-3330-2764 